\title{
Construction and Practice of Blended Teaching Model in the Context of Big Data: A Case Study of ESP Medical English
}

\author{
Yajun Chen ${ }^{1, *}$ \\ ${ }^{1}$ School of Humanities, Social Sciences and Foreign Languages, Baotou Medical College, Baotou, Inner Mongolia \\ 014040, China \\ *Corresponding author. Email: 102013076@btmc.edu.cn
}

\begin{abstract}
The arrival of the Big Data era has laid the foundation for the blended teaching. Based on the concept of blended teaching, this paper aims to improve the medical English proficiency of medical college students in Inner Mongolia through integrating network information technology with various teaching platforms and to design a blended teaching model for ESP medical English courses. This paper used empirical research methods to test the validity of the teaching model from three aspects: students' satisfaction, class participation and learning outcomes. Through empirical analysis, it was found that blended teaching model can significantly improve students' satisfaction, class participation and learning outcomes.
\end{abstract}

Keywords: big data; blended teaching; ESP; medical English

\section{INTRODUCTION}

In 2002, Smith J and Elliott Macie put forward the concept of Blended Learning for the first time by combining networked learning technology with traditional learning concepts.[1] Blended teaching refers to the teaching model that combines Internet technology with face-to-face teaching. Although Porter.W said as early as 2014 that "blended teaching will become the regular model of teaching in the future",[2] the popularity rate of this teaching model has not been high. It was not until the outbreak of COVID-19 epidemic in early 2020 that the blended teaching model truly ushered in a period of rapid development. However, according to the survey, many problems have been found in the teaching process of ESP (English for Specific Purposes) medical English courses in several medical colleges of Inner Mongolia, such as low students' participation, lack of autonomous learning ability and poor teacher-student interaction, etc. Therefore, this paper adopted an innovative blended teaching concept so as to design a specialized and standardized blended teaching model for the medical English courses of medical colleges in Inner Mongolia.

\section{CONSTRUCTION AND PRACTICE OF BLENDED TEACHING MODEL}

The ancient Roman educator Protarch once said that "A child is not a vase to be filled, but a fire to be lit."[3] The lack of students' interest in learning leads to their poor participation in class. In order to fundamentally enhance students' interest in learning and their class participation, this paper designed a new blended teaching model for the course of medical English.

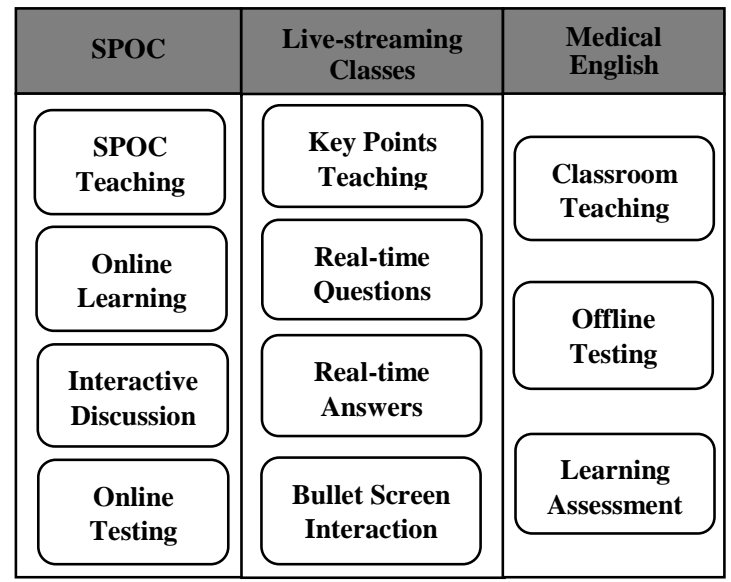

Figure 1. The new blended teaching model

The "Medical English" course in Fig.1 is a public compulsory course offered by a medical college in Inner Mongolia. The main objective of this course is mainly to cultivate students' English application ability and medical humanistic quality. The course consists of 30 class hours and 2 credits. As shown in Fig.1, SPOC courses, online live-streaming classes and medical English constitute the core of the teaching model. The online real-time questions and answers, bullet screen interaction in live-streaming classes as well as SPOC teaching all ensured students' participation in the class. Teachers can analyze students' learning data and supervise their learning conditions at any time. 


\subsection{The Integration of Teaching Platforms}

The combination of information technology and subject curriculum is to create an ideal teaching platform by effectively integrating information technology into the teaching process. ${ }^{[4]}$ This study combines the SPOC platform, the online live-streaming class platform and the medical English platform in multiple dimensions, thereby realizing the integration of network information technology and curriculum. First of all, this study proposes a "SPOC and micro classroom" curriculum model to explore the indepth integration of new network information technology and English classroom teaching, and to better play the role of "mobile micro-learning" and other innovative curriculum models. Secondly, teachers can synchronize teaching materials with students' mobile software like Wechat and Tencent QQ through live-streaming class platforms such as "Rain Classroom" and "Tencent Class". And massive online videos and learning materials can also be sent to students' mobile phones. Finally, in order to improve students' medical English proficiency, various medical terminology learning modules are set up in the "Medical English" teaching module. Finally, teachers can test students' learning outcomes with the help of the online test software on the SPOC platform and live-streaming class platform as well as the offline test software on the medical English platform.

\subsection{The Integration of Network Information Technology}

The improvement of students' ability to use information technology for self-exploration and self-learning should be considered as the ultimate teaching goal of the schools. ${ }^{[5]}$ Various network information technologies such as online test systems and smart cloud storage can be integrated into the teaching process of "Medical English" courses. Teachers can use these kinds of intelligent technologies to supervise the learning status of students at any time. And all students' learning data can also be uploaded to the cloud storage platforms, which can be used by teachers to measure students' learning status later. Students can also use this type of online test systems to conduct self-tests and record their own learning process at any time. By connecting the classroom with network information technology, teachers and students can interact with each other anytime and anywhere. For example, students can raise a question on the Interactive Discussion section at 2 o'clock in the morning, and the professor and other classmates can answer this question as soon as they see it.

\section{EMPIRICAL RESEARCH AND TEACHING EFFECTS ANALYSIS}

\subsection{Empirical Research Process}

Gilberty and Ricardo came to a conclusion through years of teaching practice: when online teaching time accounts for $33 \%-55 \%$ of the total class hours, students will have more prominent classroom performance. ${ }^{[6]}$ The online and offline time allocation for this course is based on this ratio. In order to accurately verify the rationality and effectiveness of this teaching model, this study took the medical English course of a medical college in Inner Mongolia as the experimental course, and conducted an empirical evaluation of the teaching effects of the teaching model from three dimensions, namely students' learning outcomes, class participation and satisfaction.

This empirical study took two classes of 2020 undergraduates from a medical college as the research objects, and divided the classes into experimental classes and control classes. The number of students in the experimental class was 30 , of which 12 were male students and 18 were female students, accounting for $40 \%$ and $60 \%$ respectively. The number of students in the control class was 43 , of which 19 were male students and 24 were female students, accounting for $44 \%$ and $56 \%$ respectively. The process of this empirical study is mainly divided into two parts. First of all, in the early stage of the experiment, the teacher took the final score of the College English Test Band 4 (CET4) as the measurement standard to compare the English scores of the experimental class and the control class. An online and offline blended teaching was carried out in the experimental class, while a traditional classroom teaching was adopted in the control class. During the empirical study, in order to ensure the accuracy of the experimental data, the teaching progress and content of the experimental class and the control class were kept completely consistent. Secondly, after a semester of experiment, the teacher used the "UMOOC V8" intelligent assessment system to conduct online tests for the two classes.

\subsection{Empirical Test Results and Analysis}

\subsubsection{Analysis on Learning Outcomes}

In the early stage of the experiment, the teacher used a statistical analysis software SPSS Version 25.0 to conduct statistics on the CET4 scores of the two classes (Table 1). Statistical data showed that the average scores of the experimental class and the control class were 466.23 points and 447.54 points respectively. The significance level ( $\mathrm{P}$ value) was 0.421 , greater than 0.05 , according to independent sample t-value test. Therefore, the significance (P-value) showed that there was no significant difference in 
the average scores of CET- 4 between the experimental class and the control class.

Table 1. Comparison of average CET4 scores between experimental class and control class

\begin{tabular}{|c|c|c|c|c|}
\hline Class & $\begin{array}{c}\text { Number } \\
\text { of } \\
\text { Students }\end{array}$ & $\begin{array}{c}\text { Average } \\
\text { Scores }\end{array}$ & $\begin{array}{c}\text { T- } \\
\text { value }\end{array}$ & $\begin{array}{c}\text { P- } \\
\text { value }\end{array}$ \\
\cline { 1 - 2 } $\begin{array}{c}\text { Experimental } \\
\text { Class }\end{array}$ & 30 & 466.23 & 0.652 & 0.421 \\
\hline Control Class & 43 & 447.54 & & \\
\hline
\end{tabular}

After a semester of experiment, the teacher used the "UMOOC V8" intelligent assessment system to conduct online tests for the two classes. The online test mainly covered the medical terminology translation, medical literature reading and other fields. For the accuracy of data, the test contents of the two classes were exactly the same. In the end, the test results showed that the average scores of the experimental class and the control class were 80.65 points and 69.24 points respectively. The significance level (P value) was 0.006 , less than 0.05 . Therefore, the significance ( $\mathrm{P}$ value) showed that there was a significant difference in the test results between the experimental class and the control class.

Table 2. Comparison of the final evaluation results between experimental class and control class

\begin{tabular}{|c|c|c|c|c|}
\hline Class & $\begin{array}{c}\text { Number } \\
\text { of } \\
\text { Students }\end{array}$ & $\begin{array}{c}\text { Average } \\
\text { Scores }\end{array}$ & $\begin{array}{c}\text { T- } \\
\text { value }\end{array}$ & $\begin{array}{c}\text { P- } \\
\text { value }\end{array}$ \\
\cline { 1 - 3 } $\begin{array}{c}\text { Experimental } \\
\text { Class }\end{array}$ & 30 & 80.65 & 2.765 & 0.006 \\
\cline { 1 - 3 } Control Class & 43 & 69.24 & & \\
\cline { 1 - 3 }
\end{tabular}

Through experiment, it was not difficult to find that the online and offline blended teaching can significantly improve the learning outcomes of students. This is mainly because the blended teaching model can enable students to realize the role exchange between students and teachers through "teacher-student interaction" and "student-student mutual evaluation", which not only improves students' learning motivation but also improves their learning outcomes.

\subsubsection{Analysis on Class Participation}

According to the statistics of online learning time on livestreaming class platforms such as "Rain Classroom" as well as the background learning data of SPOC online class, 28 out of 30 students $(93.3 \%)$ in the experimental class spent $100 \%$ of their class time online. All the students answered the teacher's questions through the online realtime question session in the live-streaming class. It is worth noting that although students' overall class participation has been significantly improved, their participation in the three teaching links is not the same. Class data showed that $87.5 \%$ of students were most likely to participate in real-time answers and bullet screen interaction in live-streaming classes. In contrast, the lowest level of student participation was in the traditional medical English classroom teaching, which accounted for $68.78 \%$. Through comparative analysis of the data, it was found that the blended teaching model has significantly improved students' class participation.

\subsubsection{Analysis on Learning Satisfaction}

In order to accurately grasp the situation of students' learning satisfaction, teachers collected the data by making, distributing and analyzing questionnaires. After analyzing the questionnaires data, 29 out of 30 students (96.6\%) in the experimental class expressed their recognition for the blended teaching model, and believed that the medical English courses have quickly improved their study in terms of medical vocabulary and reading. Only one student still supported the traditional classroom teaching model in the questionnaire. The reason was that the unskilled operation of various online teaching platforms has led to low learning efficiency. The vast majority of students $(86.6 \%)$ said that the knowledge learned in the medical English courses can be used in their future clinical work. Therefore, the questionnaires data showed that students had a high degree of satisfaction with the blended teaching model, especially in the aspects of the academic vocabulary and practical knowledge in medical English courses.

\section{CONCLUSION}

Blended teaching model has become an inevitable trend of education and teaching reform in China. The new blended teaching model meets the needs of our times and is free from the geographical restrains and teaching stereotype of the traditional teaching. Based on the concept of blended teaching, this study integrated the network information technology with various teaching platforms and designed a blended teaching model for medical English courses. Through empirical analysis, it was found that blended teaching model can significantly improve students' learning outcomes, class participation and learning satisfaction. The author believes that the huge changes in teaching model, teaching content, teaching platforms and assessment methods will definitely inject new vitality into college English teaching, especially the medical English teaching in medical colleges.

\section{ACKNOWLEDGMENT}

First of all, I would like to express my sincere gratitude to my colleague Professor an Huilin for the helpful conversations that we had.

Second, I would like to extend my thanks to my students who participated in this study with great cooperation. 
Last but not the least, special thanks would go to my wife, Miao Jingyan, for her love, devotion, encouragement, patience and understanding.

\section{REFERENCES}

[1] Wang Jin and Zhao Xinping, "A study of blended teaching mode for English major in normal colleges," J. Shanxi: Theory and Practice of Education, vol. 30, 2018, pp. 45-47. (In Chinese)

[2] Porter W, "Blended learning in higher education: institutional adoption and implementation," J. England: Computers \& Education, vol. 3, 2014, pp. 185-195.

[3] Guo Yuanxiang, The Stand of Education. Anhui: Anhui Education Press, 2009, pp. 30-31. (In Chinese)
[4] He Kekang, "New development of educational technology from a perspective of blending learning," J. China: Journal of National Academy of Education Administration, vol. 9, 2005, pp. 47. (In Chinese)

[5] Feitosa de Moura Valéria and Alexandre de Souza Cesar, "The use of massive open online courses (MOOCs) in blended learning courses and the functional value perceived by students," J. England: Computers \& Education, vol. 3, 2021, pp. 161.

[6] Gilbert, J.A. and Ricardo, F.Z. "Development and implementation of a "blended" teaching course environment," J. Journal of Online Learning and Teaching, vol. 7, June 2011, pp. 244-254. 